\title{
Granulomatöse Dermatosen
}

\section{Granulomatous Diseases of the Skin}

G. Kolde

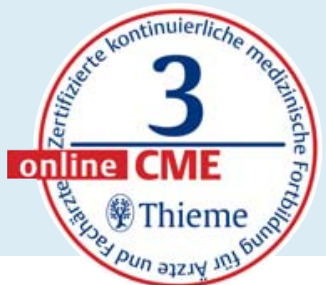

Dermatologisches Zentrum Berlin

\section{Lernziele}

$\nabla$

Kenntnisse über:

- Definition der Krankheitsgruppe

- Ätiopathogenese und Histopathologie

- Klinik und Differenzialdiagnose

- Diagnostische Sicherung

- Behandlungsmöglichkeiten

\section{Einleitung und Definition}

Die granulomatösen Dermatosen sind eine Gruppe von nicht-infektiösen entzündlichen Hauterkrankungen, die histologisch durch Ansammlungen von Histiozyten und mehrkernigen Riesenzellen im dermalen Bindegewebe gekennzeichnet sind [1]. Diese umschriebenen Zellansammlungen ( $\bullet$ Abb. 1$)$ werden als Granulom (granulum $=$ Körnchen) bezeichnet.

Alle granulomatösen Entzündungen entstehen als Abwehrreaktion gegen körperfremde Materialien, die nicht durch andere Mechanismen aus dem Gewebe eliminiert werden können. Hierzu zählen infektiöse Organismen wie Bakterien und Pilze und nicht-infektiöse Materialien wie Zerfallsprodukte des Bindegewebes und Fremdkörper [2]. Es kommt zu einer Einwanderung von Monozyten und deren Differenzierung zu Histiozyten und Riesenzellen [3]. Das körperfremde Material wird dann durch tuberkuloide, sarkoidale und andere Granulome eingemauert und vom umliegenden Gewebe abgeschottet. Der histologische Aufbau der Granulome erlaubt nur sehr begrenzte Rückschlüsse auf die Art und Eigenschaften des umschlossenen Materials [2]. Daher ist bei den meisten granulomatösen Dermatosen nicht genau bekannt, wodurch die Abwehrreaktion hervorgerufen wird und ob die Granulombildung durch unspezifisch entzündliche, spezifisch immunologische oder sogar durch beide Vorgänge vermittelt und unterhalten wird.

Im Vergleich $\mathrm{zu}$ anderen entzündlichen Hautkrankheiten sind granulomatöse Dermatosen sel-

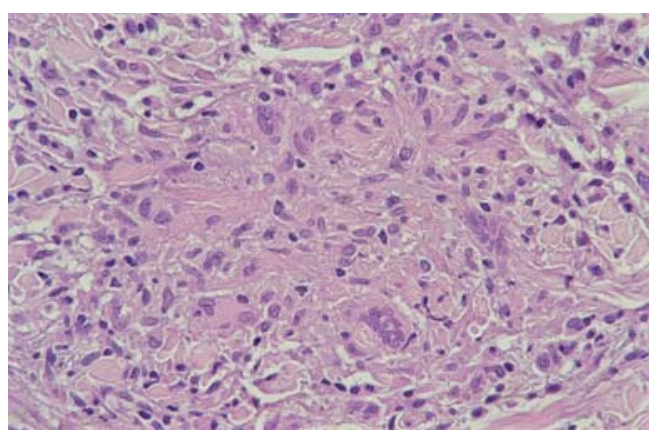

Abb. 1 Histologie eines Granuloms mit Histiozyten und mehrkernigen Riesenzellen (HE-Färbung, Originalvergrößerung $400 \times$ ).

ten und für jeden Hautarzt eine Herausforderung, da

- die klinischen Erscheinungsbilder sehr variabel sind,

- der Krankheitsverlauf chronisch oder wellenförmig ist und

- die Behandlung schwierig und manchmal sogar unbefriedigend ist.

Die Gruppe der granulomatösen Dermatosen ist im deutschsprachigen und internationalen Schrifttum nicht einheitlich definiert. In diesem Artikel werden die klassischen Vertreter der Krankheitsgruppe dargestellt.

Granulomatöse Dermatosen sind eine Gruppe von nicht-infektiösen Hauterkrankungen mit typischer Histologie.

\section{Sarkoidose}

\section{$\nabla$}

Die Sarkoidose ist eine Multisystemerkrankung, die sich an einem oder häufiger an mehreren Organsystemen abspielt. Hauptsächlich betroffen sind intrathorakale Lymphknoten, Lunge, Haut und Augen [4]. Eine kutane Beteiligung findet sich bei 25-35\% der Patienten und kann erstes klinisches Zeichen der Erkrankung sein.
VNR

2760512014144210423

\section{Bibliografie}

DOI http://dx.doi.org/

10.1055/s-0034-1365477

Akt Dermatol 2014; 40: 193-204

(c) Georg Thieme Verlag KG

Stuttgart · New York

ISSN 0340-2541

Korrespondenzadresse

Prof. Dr. med. Gerhard Kolde

Dermatologisches Zentrum

Potsdamer Chaussee 80

14129 Berlin

gerhard.kolde@arcor.de 


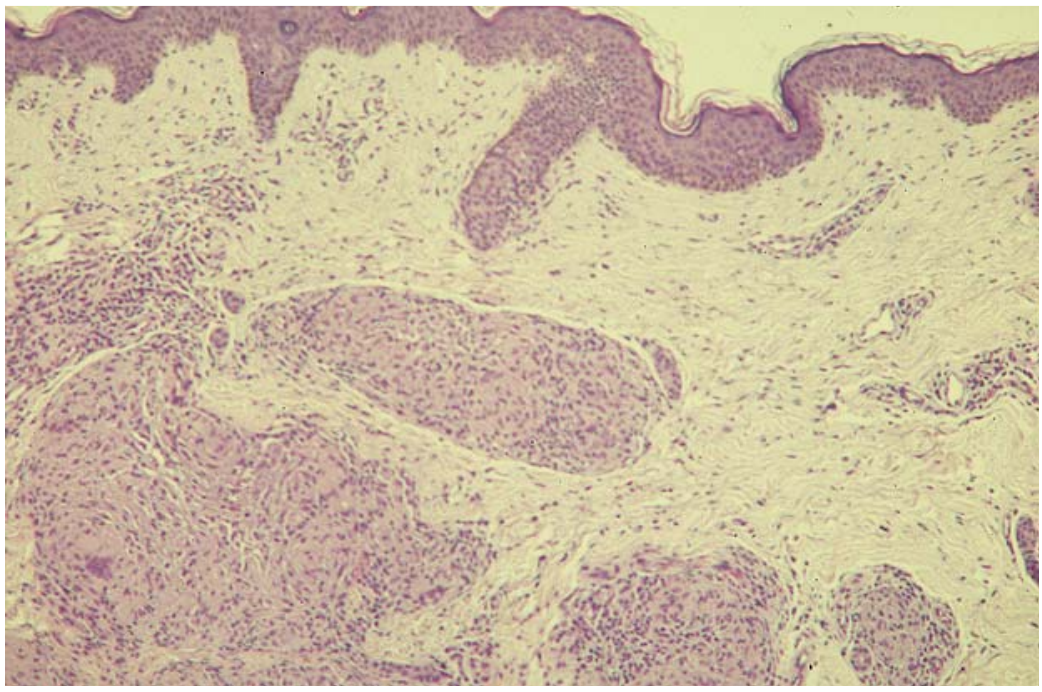

Abb.2 Histologie der Sarkoidose mit multiplen nacktzelligen epitheloidzelligen Granulomen in der Dermis (HE-Färbung, Originalvergrößerung 100×).

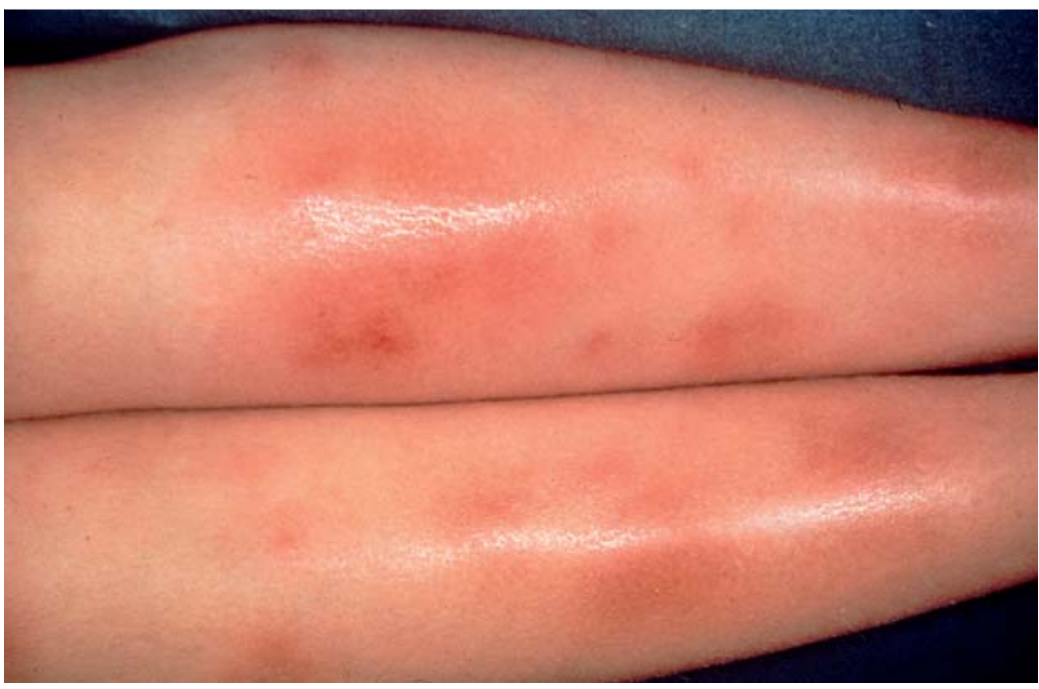

Abb. 3 Erythemata nodosa bei akuter Sarkoidose.

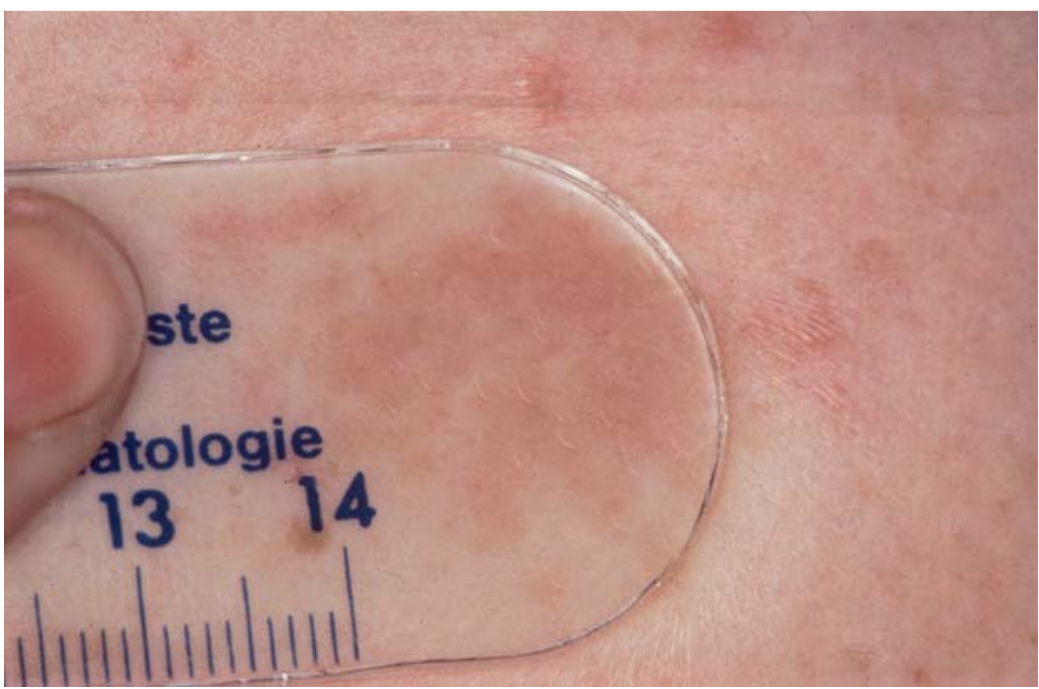

Abb.4 Apfelgeleeartiger Farbton auf Glasspateldruck.

\section{Ätiopathogenese}

Gesichert ist eine T-Zell-vermittelte granulomatöse Immunreaktion vom Th1-Typ [5]. Die Immunreaktion wird durch das Cytokin TNF- $\alpha$, die Interleukine 12, 15 und 18 sowie das Chemokin MIP-1 eingeleitet und unterhalten. Es besteht eine genetische Prädisposition mit verschiedenen HLA-Assoziationen. Die Identität des auslösenden Antigens ist trotz intensiver Forschungen nicht geklärt. Diskutiert werden ein noch nicht definiertes Autoantigen oder infektiöse Antigene wie Mykobakterien und Herpesviren [6].

\section{Histopathologie}

Charakteristisch für alle betroffenen Organe sind epitheloidzellige Granulome, die kaum Lymphozyten und andere Entzündungszellen enthalten und daher als nackte oder nacktzellige Granulome bezeichnet werden ( $\boldsymbol{\bullet}$ Abb.2) $[7,8]$. Epitheloidzellen sind große Histiozyten mit dem Aussehen von Epithelzellen. In den mehrkernigen Riesenzellen können sternförmige Asteroidkörperchen und rund-ovale basophile SchaumannKörper nachgewiesen werden. Beide Strukturen sind typisch aber nicht spezifisch für die Diagnose einer Sarkoidose.

\section{Klinik}

Das typische Hautzeichen einer akuten Sarkoidose ist das Erythema nodosum ( $\bullet$ Abb.3). Es findet sich bei etwa $25 \%$ aller Patienten und ist häufig mit einer frühen Sarkoidose der hilären Lymphknoten assoziiert [9]. Die Kombination von Erythema nodosum, hilärer Lymphadenopathie und Arthritis wird als Löfgren-Syndrom bezeichnet.

Die granulomatösen Manifestationen der Sarkoidose an der Haut sind vielgestaltig [10-12]. Ein wichtiges klinisch-diagnostisches Merkmal aller Hautläsionen ist der gelblich-graue, an Apfelgelee erinnernde Farbton auf Glasspateldruck (৫ Abb.4).

Die häufige kleinknotige Hautsarkoidose ist durch multiple, $2-5 \mathrm{~mm}$ große, lividrote und derbe Makeln und Papeln gekennzeichnet ( $\bullet$ Abb.5a). Die Läsionen finden sich vor allem an den Streckseiten der Extremitäten und an Nase, Ohren und Wangen. Sie können anulär angeordnet sein und zu Plaques konfluieren. Wichtige Differenzialdiagnosen sind Lichen planus, lichenoides Arzneimittelexanthem und Lues II.

Die ebenfalls häufige großknotige Form zeigt sich mit einem oder mehreren, bis zu einigen Zentimetern großen, blau- bis braunroten und derben Knoten sowie Plaques im Bereich von Gesicht, Stamm und proximalen Extremitäten $(\bullet$ Abb.5b). Die homogenen und ringförmigen Läsionen sind manchmal von Teleangiektasien durchzogen und können sogar ulzerieren. Wichtige Differenzialdiagnosen sind Fremdkörpergranulom, Granuloma anulare, Necrobiosis lipoidica und Lupus vulgaris. 

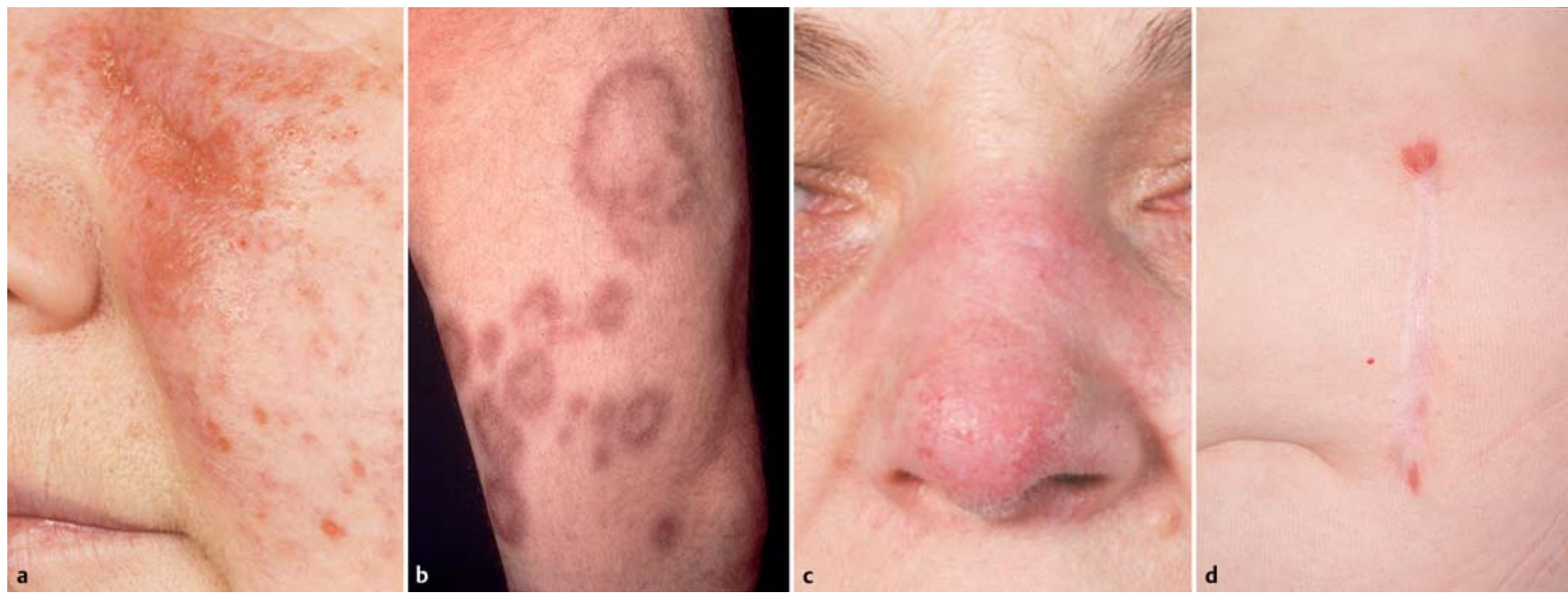

Abb.5 Sarkoidose. a Kleinknotige Form mit Makeln und Papeln an der linken Wange [13]. b Großknotige Form mit ringförmigen Plaques am Oberschenkel. c Lupus pernio mit unscharfem lividroten Infiltrat an der Nase [13]. d Narbensarkoidose mit rot-braunen Knoten in alter Narbe.

Im Gesichtsbereich imponiert die großknotige Sarkoidose auch als Lupus pernio mit lividroten und an Frostbeulen erinnernden, unscharfen und polsterartigen Infiltraten $(\bullet \mathbf{A b b} . \mathbf{5 c})$. Frauen sind deutlich häufiger betroffen als Männer. Bis zu 75\% der Patienten haben eine Lungensarkoidose.

Die subkutan-knotige Form wird auch als DarierRoussy-Sarkoidose bezeichnet und ist durch schmerzlose, seltener schmerzhafte, zumeist hautfarbene und derbe Knoten an den Extremitäten gekennzeichnet. Eine Beteiligung anderer Organe besteht fast immer. Ein subkutanes Granuloma anulare und Rheumaknoten können zumeist nur histologisch ausgeschlossen werden.

Die Narbensarkoidose ist eine umschriebene Erkrankungsform, die sich als zunächst rote, später bräunliche Infiltration in zumeist alten Narben zeigt $(\bullet$ Abb.5d). Sie muss differenzialdiagnostisch vor allem von Keloiden und Fremdkörpergranulomen abgegrenzt werden.

In selten Fällen kann sich eine kutane Sarkoidose als Erythrodermie, mit psoriasiformen, verrukösen oder ulzerierten Infiltraten, an Nägeln und Mundschleimhaut manifestieren [10].

Das Erythema nodosum ist typisch für eine akute Sarkoidose. Alle Formen der Hautsarkoidose zeigen einen apfelgeleeartigen Farbton auf Glasspateldruck.

\section{Diagnose}

Der klinische Verdacht auf eine kutane Sarkoidose muss histologisch durch den Nachweis von nackten epitheloidzelligen Granulomen gesichert werden [10-12]. Kein anderer Laborparameter und kein bildgebendes Verfahren sind zur diagnostischen Sicherung geeignet. Der Krankheitsverlauf kann hingegen gut durch Bestimmung der Spiegel des Angiotensin-konvertierenden Enzyms und des Interleukin-2-Rezeptors kontrolliert werden. Bei histologisch nachgewiesener Sarkoidose muss

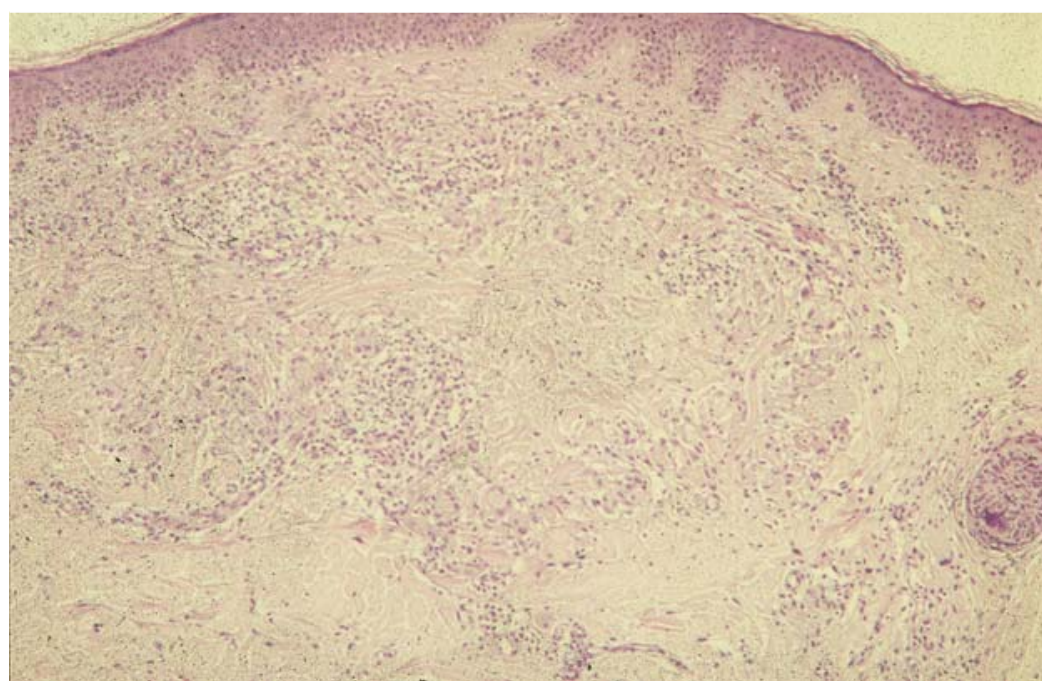

Abb. 6 Histologie des Granuloma anulare mit Palisadengranulom in der oberen und mittleren Dermis (HE-F̈rrbung, Originalvergrößerung 100×).

in interdisziplinärer Zusammenarbeit eine Manifestation an anderen Organen geprüft werden.

Eine kutane Sarkoidose kann nur histologisch gesichert werden.

Therapie

Eine Sarkoidose der Haut sollte behandelt werden, wenn

- es sich um eine ausschließlich kutane und progressive Erkrankung handelt,

- seitens des übrigen Organbefalls keine Notwendigkeit einer Therapie besteht und

- die erfolgreiche Behandlung des sonstigen Organbefalls zu keiner Besserung der kutanen Läsionen führt.

Therapie der 1.Wahl sind potente topische und intraläsionale Glukokortikoide [9-12]. Topische Calcineurin-Inhibitoren waren in mehreren Fall- 


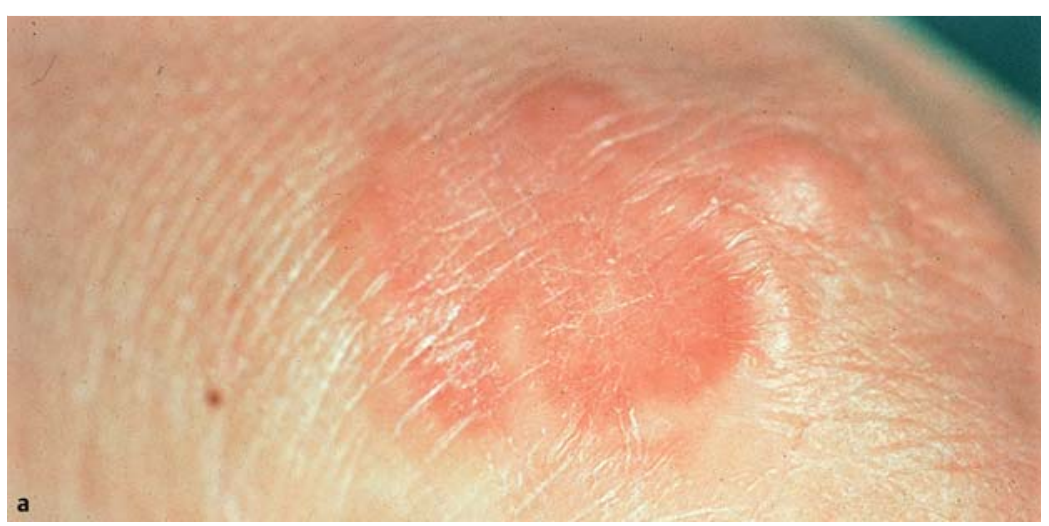

Abb.7 Granuloma anulare. a Lokalisierte Form am Handrücken. b Disseminierte Form mit unterschiedlich großen und konfluierenden Läsionen am Unterarm.

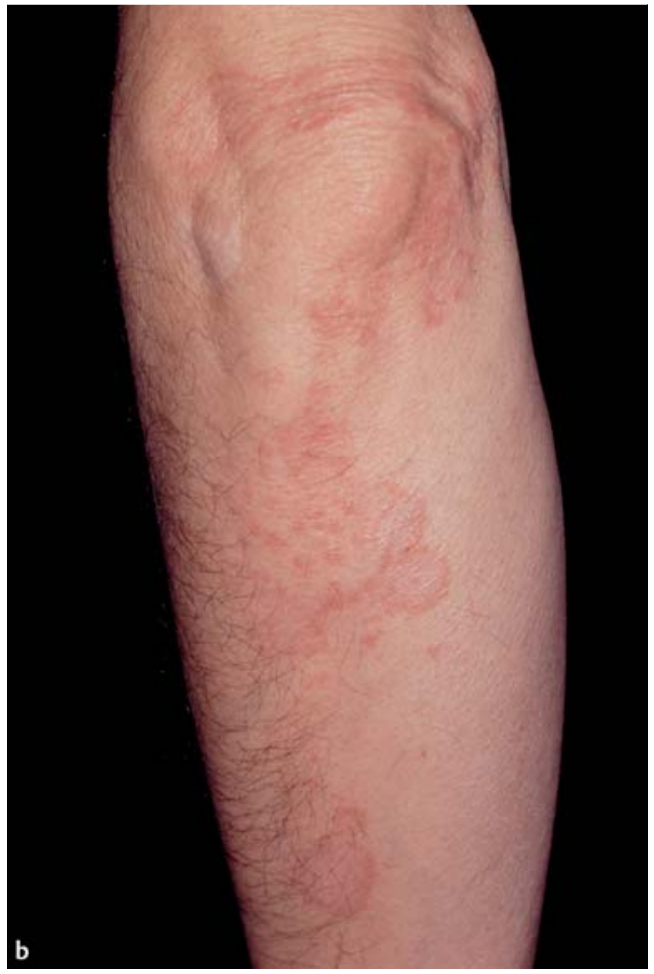

serien erfolgreich. Über gute Therapieerfolge wurde durch Fototherapie mit PUVA und UVA1 berichtet. Orale Glukokortikoide sind Mittel der 1. Wahl bei nicht auf topische Behandlungen ansprechenden und schnell progressiven Verlaufsformen. Diese werden entweder alleine oder in Kombination mit immunmodulierenden und immunsuppressiven Medikamenten eingesetzt. Bei anderweitig therapieresistenten Erkrankungen haben sich Methotrexat (10-25 mg/Woche) und in neuerer Zeit zunehmend TNF- $\alpha$-Antagonisten bewährt.

\section{Granuloma anulare}

\section{$\nabla$}

Die Erstbeschreibung dieser recht häufigen $\mathrm{Er}$ krankung erfolgte 1895 durch den britischen Dermatologen T.C. Fox, der Terminus Granuloma anulare wurde schon 1902 von H. Radcliffe-Crocker geprägt. Dennoch ist die Ätiologie bis heute nur ansatzweise bekannt, und die Behandlung ist immer noch rein empirisch.

\section{Ätiopathogenese}

Die Ätiopathogenese ist nicht genau bekannt. In immunhistologischen, biochemischen und immunologischen Untersuchungen konnte eine T-Zellvermittelte granulomatöse Entzündungsreaktion vom Th1-Typ nachgewiesen werden [14,15]. Nicht geklärt ist jedoch, welche Strukturen des dermalen Bindegewebes als Antigen fungieren. Insektenstiche, Traumen, Lichtexposition etc. wurden wiederholt als Auslöser der Krankheit beschrieben.

\section{Histopathologie}

Es gibt 3 verschiedene histologische Muster [16, 17]. Typisch für die Diagnose sind sog. Palisadengranulome aus Histiozyten, Riesenzellen und wenigen Lymphozyten, die ringförmig um nekrobiotisch degeneriertes Bindegewebe angeordnet sind ( $\bullet$ Abb.6). Das nekrobiotische Bindegewebe stellt sich mit Muzinfärbungen positiv dar. Bei der 2 . interstitiell-granulomatösen Variante dominieren die histiozytären Infiltrate, und die Degeneration des Bindegewebes wird erst durch Muzinfärbung erkennbar. Die 3. und seltene sarkoidale Variante ist nur mittels Muzinfärbung von einer Sarkoidose zu unterscheiden.

\section{Klinik}

Das Granuloma anulare tritt lokalisiert, disseminiert, subkutan und als perforierende Variante auf [18-21].

Die häufige lokalisierte Form (ca. 75\% der Erkrankungen) manifestiert sich zumeist an den Rückseiten von Händen und Füßen ( $\mathbf{A}$ bb.7a). Zwei Drittel der Patienten sind jünger als 30 Jahre, Frauen sind doppelt so häufig betroffen wie Männer. Klinisch imponieren ringförmig angeordnete, hautfarbene bis leicht gerötete Papeln. Die Haut im Zentrum stellt sich regelrecht oder leicht eingesunken dar. Subjektiv bestehen üblicherweise keine Beschwerden. Differenzialdiagnostisch müssen vor allem eine kutane Sarkoidose und Necrobiosis lipoidica ausgeschlossen werden. Bei der disseminierten Form (ca. 8-15\% der Erkrankungen) bestehen multiple anuläre Läsionen am gesamten Integument ( $\mathbf{A b} \mathbf{b}$. $7 \mathbf{b}$ ). Die betroffenen Patienten sind zumeist Kinder oder Patienten im mittleren und höheren Erwachsenenalter. Das männliche Geschlecht überwiegt. Bis zu 20\% der Patienten mit disseminierten Granuloma anulare haben oder entwickeln einen Diabetes mellitus [22]. Nicht gesichert ist hingegen eine gehäufte Assoziation mit Schilddrüsen- und Lebererkrankungen, rheumatoider Arthritis, HIVInfektionen und mit Malignomen [23]. Die Differenzialdiagnose ist breit und umfasst alle Erkrankungen, die durch multiple anuläre und nummuläre Erytheme und Papeln gekennzeichnet sind. Hierzu zählen in erster Linie eine kutane Sarkoidose, Necrobiosis lipoidica, Tinea und UrtikariaVaskulitis. 
Die seltene subkutane Form ist durch derbe, hautfarbene und schmerzlose Knötchen und Knoten bevorzugt an den Beinen gekennzeichnet. Zumeist sind kleine Kinder betroffen. Bis zu 50\% der Patienten weisen gleichzeitig auch typische Hautläsionen auf, sodass schon klinisch eine subkutane Sarkoidose, Rheumaknoten und Pannikulitiden ausgeschlossen werden können.

Bei der sehr seltenen perforierenden Form wird das degenerierte Bindegewebe über die Epidermis ausgeschleust. Bevorzugt an den Streckseiten der Extremitäten zeigen sich genabelte oder ulzerierte Papeln. Differenzialdiagnostisch müssen andere perforierende Dermatosen wie der Morbus Kyrle und die perforierende Follikulitis ausgeschlossen werden.

\section{Diagnose}

Die Diagnose kann bei der lokalisierten Variante zumeist klinisch gestellt werden. Bei den anderen Varianten und bei allen zweifelhaften Fällen sollte die Diagnose histologisch gesichert werden. Dazu sollten entweder eine vollständige Läsion oder eine Probebiopsie, die den anulären Rand und das Zentrum enthält, untersucht werden.

\section{Therapie}

Das lokalisierte Granuloma anulare heilt bei über $70 \%$ der Patienten innerhalb eines Jahres spontan ab. Die anderen Varianten zeigen eine deutlich geringere Spontanheilung.

Die Palette der eingesetzten Behandlungsverfahren ist aufgrund fehlender kontrollierter Studien sehr breit [22] und in $\bullet$ Tab. 1 dargestellt. Wichtig für die Praxis ist, dass topische Glukokortikoide weiterhin Therapie der ersten Wahl bei der lokalisierten Erkrankung sind. Bei disseminierten Erkrankungen wurden hingegen gute Erfolge durch eine Fototherapie mit UVB $311 \mathrm{~nm}$, PUVA und UVA1 erzielt. Die fotodynamische Behandlung mit 5-Aminolävulinsäure und ihrem Methylester ist nach mehreren Berichten eine viel versprechende neue Behandlungsmethode $[24,25]$. Der Einsatz der TNF- $\alpha$-Antagonisten Adalimumab, Etanercept und Infliximab hat sich vor allem bei anderweitig therapieresistenten Krankheitsfällen bewährt.

Das klinische Bild des lokalisierten Granuloma anulare ist zumeist diagnostisch. Die anderen Formen sind klinisch weniger eindeutig und sollten histologisch gesichert werden.
Tab. 1 Therapieoptionen bei Granuloma anulare.

\begin{tabular}{|l|l|}
\hline Topische Behandlung & Glukokortikoide (auch intraläsional) \\
\hline $\begin{array}{l}\text { Erste Wahl } \\
\text { Sonst }\end{array}$ & Tacrolimus, Pimecrolimus \\
\hline $\begin{array}{l}\text { Physikalische Behandlung } \\
\text { Kryotherapie }\end{array}$ & Distickstoffoxid, flüssiger Stickstoff \\
\hline Fototherapie & UVB 311 nm, PUVA, UVA1 \\
\hline Fotodynamische Behandlung & 5-Aminolävulinsäure, Methyl-5-amino-4-oxopentanoat \\
\hline Lasertherapie & $\mathrm{CO}_{2}$-Laser, gepulster Farbstofflaser 585 nm, Nd:Yag-Laser \\
\hline Systemische Behandlung & $\begin{array}{l}\text { Chloroquin, Dapson, Etretinat, Fumarsäure, Hydroxy- } \\
\text { chloroquin, Isotretinoin, Pentoxifyllin }\end{array}$ \\
\hline Immunmodulatoren & Ciclosporin, Methotrexat \\
\hline Immunsuppressiva & Adalimumab, Etanercept, Infliximab \\
\hline Biologics &
\end{tabular}
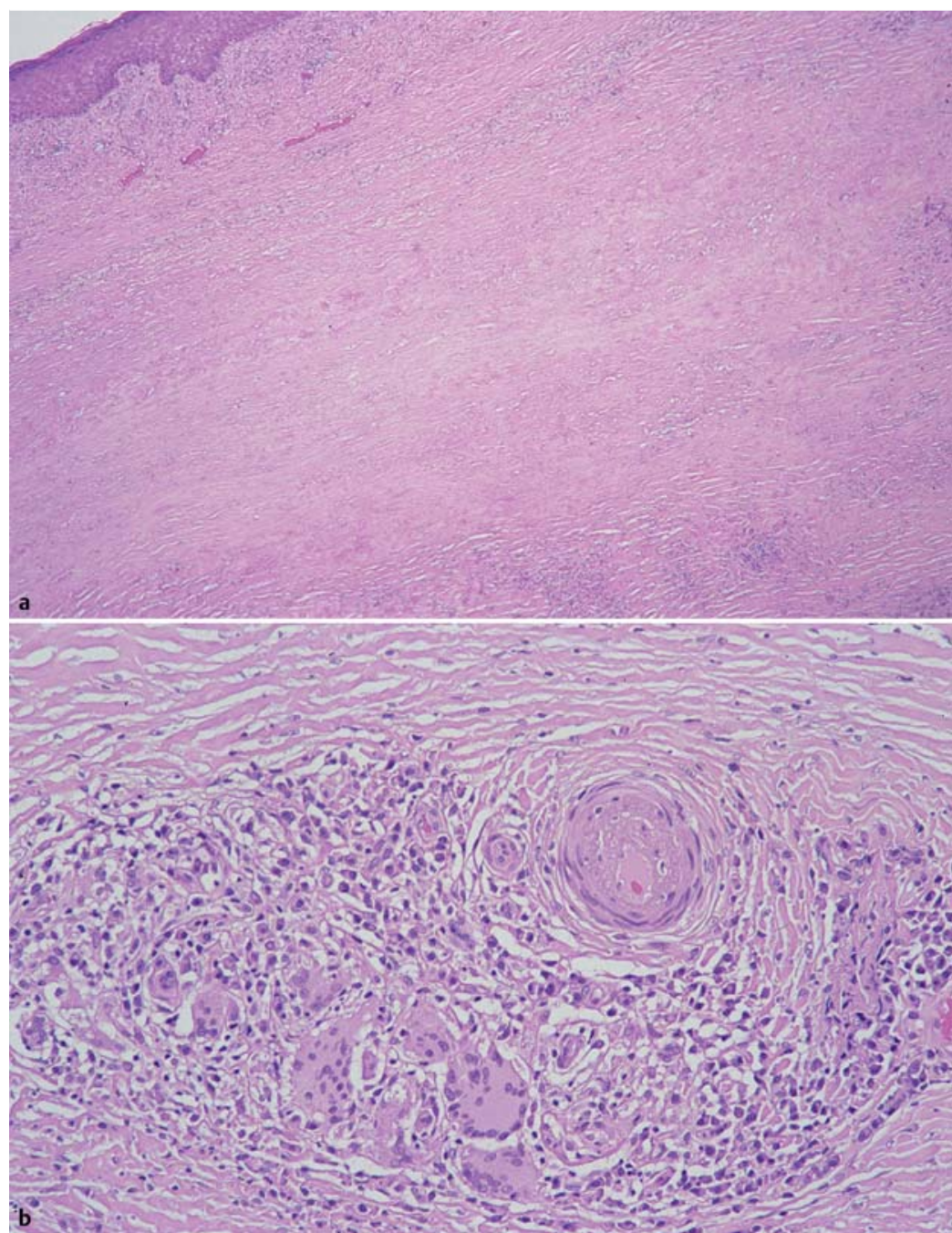

Abb. 8 Histologie der Necrobiosis lipoidica. a Palisadengranulom mit ausgedehnter Nekrobiose des dermalen Bindegewebes (HE-Färbung, Originalvergrößerung 100×). b Peripheres Granulom mit zahlreichen mehrkernigen Riesenzellen (HE-Färbung, Originalvergrößerung $400 \times)$.

\section{Necrobiosis lipoidica}

$\nabla$

Die Erkrankung ist häufig mit einem Diabetes mellitus assoziiert. Nach unterschiedlichen epidemiologischen Studien haben 10 bis $65 \%$ der Patienten einen Diabetes mellitus [23, 26]. Andererseits leidet weniger als $1 \%$ der Diabetiker gleich- zeitig an einer Necrobiosis lipoidica. Da auch die optimierte Behandlung des Diabetes nicht zu einer Besserung der Hautsymptomatik führt, ist ein kausaler Zusammenhang zwischen den Erkrankungen fraglich [23]. 


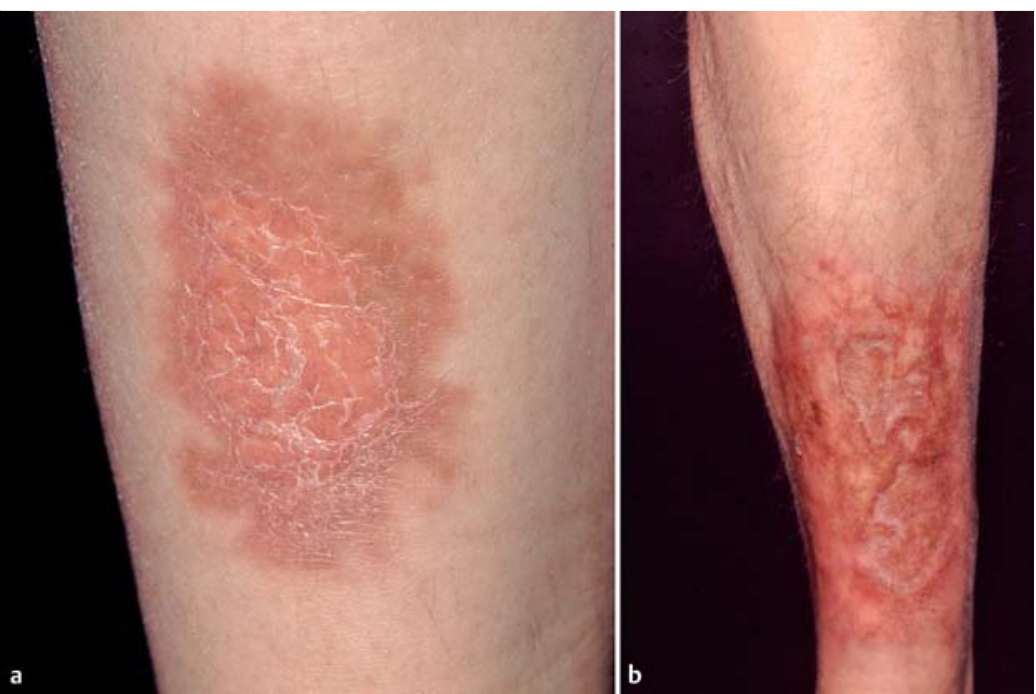

Abb.9 Necrobiosis lipoidica. a Typischer Plaque am Unterschenkel. b Ausgedehnter Befund am Unterschenkel mit zentralen Vernarbungen nach Ulzerationen.

Tab. 2 Therapieoptionen bei Necrobiosis lipoidica.

\begin{tabular}{|c|c|}
\hline Allgemeine Maßnahmen & Vermeidung von Traumen zur Vorbeugung von Ulzerationen \\
\hline \multicolumn{2}{|l|}{ Topische Behandlung } \\
\hline Erste Wahl & Glukokortikoide (auch intraläsional) \\
\hline Sonst & Tacrolimus, Tretinoin \\
\hline Fototherapie & PUVA, UVA1 \\
\hline \multicolumn{2}{|l|}{ Systemische Behandlung } \\
\hline Durchblutungsförderung & ASS und Dipyrimadol, Pentoxifyllin, Ticlopidin \\
\hline Immunmodulatoren & Chloroquin, Pentoxifyllin, Thalidomid, Fumarsäure \\
\hline Immunsuppressiva & Ciclosporin, Mycophenolatmofetil \\
\hline Biologics & Infliximab (auch intraläsional) \\
\hline Chirurgische Behandlung & tiefe Exzision der gesamten Läsion \\
\hline
\end{tabular}

\section{Ätiopathogenese}

Die Ätiopathogenese ist nicht geklärt. Es gibt gute Anhaltspunkte dafür, dass die degenerativen Veränderungen des dermalen kollagenen Bindegewebes Folge einer diabetischen Mikroangiopathie sind $[27,28]$. Dieses veränderte Kollagen soll dann aufgrund seiner entzündlichen Eigenschaften eine unspezifische granulomatöse Entzündungsreaktion induzieren.

\section{Histopathologie}

Unter einer normalen oder atrophisierten Epidermis finden sich in der gesamten Dermis umschriebene Areale von nekrobiotisch degeneriertem Bindegewebe mit typischen Einlagerungen von Lipid ( $\bullet$ Abb.8a) $[29,30]$. Diese Areale sind häufig parallel zur epidermalen Oberfläche ausgerichtet und werden an der Peripherie von Histiozyten, zahlreichen mehrkernigen Riesenzellen und einigen Lymphozyten und Plasmazellen umgeben ( $\bullet$ Abb.8b), sodass Palisadengranulome wie beim Granuloma anulare resultieren. Die Muzinfärbung ist jedoch bei der Necrobiosis lipoidica negativ.

\section{Klinik}

Bevorzugt an den Streckseiten der Unterschenkel imponieren scharf und unregelmäßig begrenzte, plattenartige Plaques mit einem gelben bis braungelben, häufig sklerotischen Zentrum und einem leicht erhabenen, lividen bis braunroten Rand ( $\triangle$ Abb.9a) [31-33]. Das Zentrum ist von Teleangiektasien durchzogen. Zumeist bestehen mehrere Plaques, und kleinere Läsionen konfluieren zu größeren. Bis zu 35\% der Patienten entwickeln nach minimalen Traumen schlecht heilende und deutlich schmerzhafte Ulzerationen und tiefe Vernarbungen ( $\bullet$ Abb.9b). Unklar ist bis heute, ob die wiederholt beschriebene Entwicklung eines Plattenepithelkarzinoms in den Läsionen tatsächlich Folge der Erkrankung oder nicht eher Folge einer chronischen Ulzeration ist [26].

Die Differenzialdiagnose umfasst in erster Linie ein disseminiertes Granuloma anulare, eine kutane Sarkoidose und zirkumskripte Sklerodermie. Bei Diabetikern ist zusätzlich an eine diabetische Dermopathie [34] und an eine Lipodermatosklerose [35] zu denken.

Bis zu 35\% der Patienten mit Necrobiosis lipoidica entwickeln schlecht heilende und sehr schmerzhafte Ulzerationen, in denen Plattenepithelkarzinome entstehen können.

\section{Diagnose}

In typischen Fällen kann die Diagnose ausschließlich klinisch gestellt werden. Bei allen zweifelhaften oder unklaren Fällen sollte eine histologische Sicherung erfolgen. Dazu sollten entweder eine vollständige Läsion oder eine Probebiopsie, die den anulären Rand und das Zentrum enthält, untersucht werden. Der untersuchende Histologe sollte unbedingt über die klinischen Verdachtsund Differenzialdiagnosen informiert werden, da die Abgrenzung von einem Granuloma anulare häufig nur mittels Muzinfärbung möglich ist. Bei gesicherter Diagnose sollte ein assoziierter Diabetes ausgeschlossen werden.

\section{Therapie}

Die Behandlung ist schwierig und häufig unbefriedigend. Da bis heute keine kontrollierten und randomisierten Studien vorliegen, ist die Palette der eingesetzten Behandlungsverfahren ähnlich breit wie beim Granuloma anulare ( $\bullet$ Tab.2) [26]. Wichtig ist, dass topische Glukokortikoide Therapie der ersten Wahl sind. Vergleichsweise gute Erfolge wurden auch mit PUVA- und UVA1-Behandlungen erzielt. Cyclosporin und Mycophenolatmofetil wurden vor allem bei der ulzerierten Necrobiosis lipoidica erfolgreich eingesetzt, wobei es jedoch nach Absetzen der Behandlung schnell zu einem Rezidiv kam. Bei anderweitig therapieresistenten Erkrankungen kann der TNF$\alpha$-Antagonist Infliximab systemisch und intraläsional eingesetzt werden. Eine chirurgische Be- 
handlung sollte Ausnahmefällen vorbehalten sein, da die Läsionen zur Vermeidung eines Rezidivs bis zur tiefen Faszie und dem Periost exzidiert und mit Spalthaut versorgt werden müssen.

\section{Anulär elastolytisches Riesenzell- granulom \\ $\checkmark$}

Die seltene Erkrankung wurde 1975 als eigenständiges Krankheitsbild von der Necrobiosis lipoidica und dem Granuloma anulare abgegrenzt, was jedoch noch immer umstritten ist. Aufgrund der bevorzugten Manifestation in sonnengeschädigter Haut wurde sie von O'Brien zunächst als aktinisches Granulom bezeichnet [37]. Die heute international gebräuchliche Bezeichnung als anulär elastolytisches Riesenzellgranulom geht auf Hanke et al. zurück [37].

\section{Ätiopathogenese}

Nicht geklärt. Es wird vermutet, dass die elastischen Fasern durch Sonnenlicht oder andere Mechanismen antigene Eigenschaften erwerben und dadurch eine T-Zell-vermittelte granulomatöse Entzündungs- und Abräumreaktion induzieren [38].

\section{Histopathologie}

In der oberen Dermis finden sich Infiltrate aus Histiozyten, zahlreichen mehrkernigen Riesenzellen und wenigen Lymphozyten ( $\bullet$ Abb. 10) [40, 41]. Elastische Fasern fehlen im Zentrum der Läsionen vollständig, im Randbereich sind sie fragmentiert und werden von den Histiozyten und Riesenzellen phagozytiert. Diese Elastophagozytose ist letztendlich diagnostisch beweisend.

\section{Klinik}

Betroffen sind Patienten im mittleren bis höheren Lebensalter, die häufig Sonnenschäden an der übrigen Haut aufweisen $[42,43]$. Die ringförmigen Plaques haben einen Durchmesser von bis $\mathrm{zu} 10 \mathrm{~cm}$ und bestehen aus einem hautfarbenen bis rotbraunen, derben Randwall und einem leicht atrophen und hypopigmentierten Zentrum ( $\bullet$ Abb.11). Der Randwall kann sich aus dicht stehenden kleinen Papeln aufbauen. Eine seltene Variante der Erkrankung ist nur papulös [45]. Zumeist bestehen mehrere anuläre Läsionen in Nacken, Gesicht, Dekollete und an den Streckseiten der Unterarme. Bei einigen Patienten wurde eine Assoziation mit Diabetes mellitus, Lymphomen und Leukämien beschrieben [46-48].

Die wichtigste Differenzialdiagnose ist die Granulomatosis disciformis chronica et progressiva [43]. Diese Sonderform der Necrobiosis lipoidica manifestiert sich ebenfalls häufig im Gesichtsbereich und weist nicht die gelbliche Farbe und Teleangiektasien einer Necrobiosis lipoidica auf.

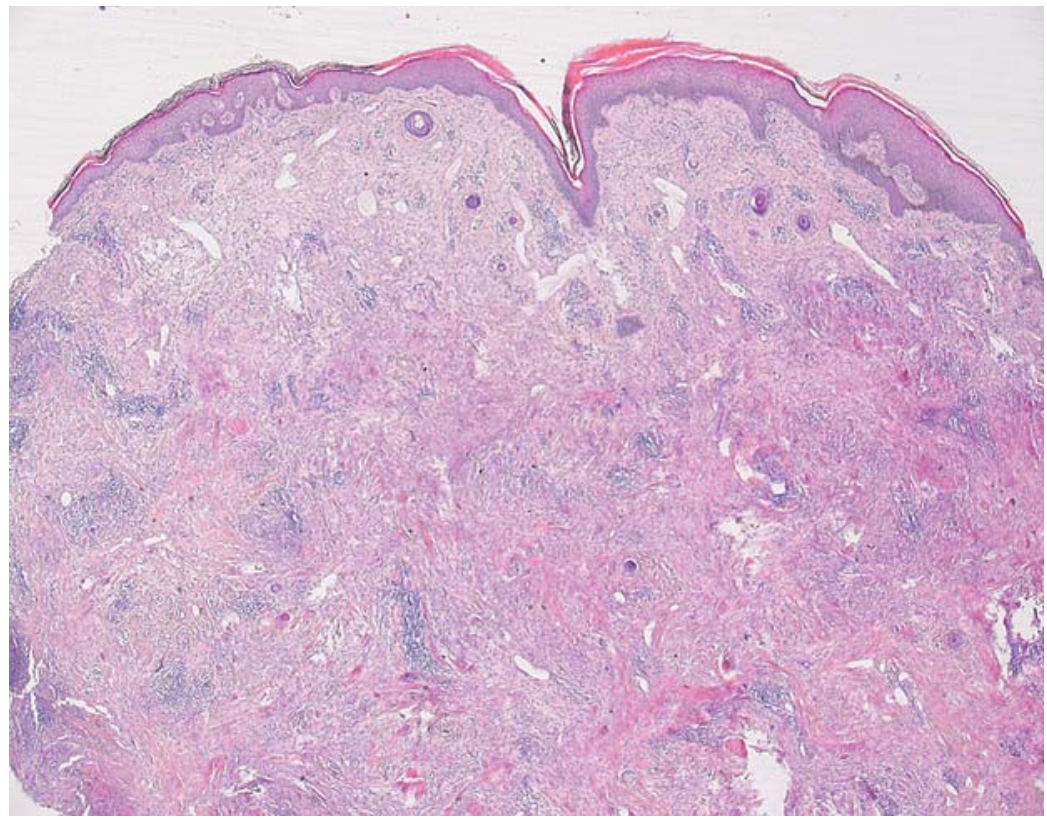

Abb.10 Histologie des anulär elastolytischen Riesenzellgranuloms mit zentralem Verlust der elastischen Fasern und peripheren Granulomen (HE-Färbung, Originalvergrößerung 100×) [39].

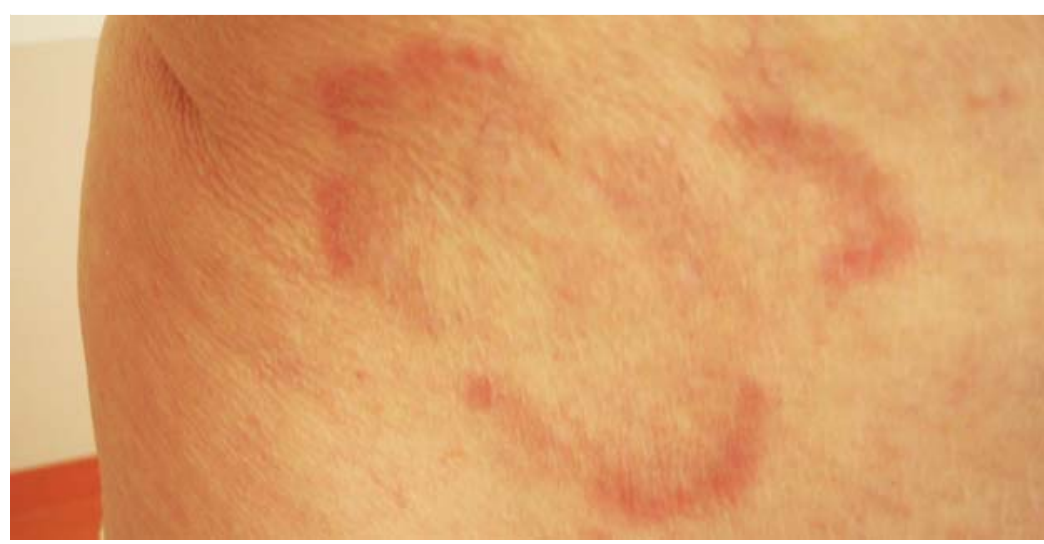

Abb.11 Anulär elastolytisches Riesenzellgranulom mit atrophem Zentrum an der Flanke [44].

Das anulär elastolytische Riesenzellgranulom ist zumeist in sonnenexponierten Hautarealen lokalisiert.

\section{Diagnose}

Die Diagnose sollte immer histologisch gesichert werden. Dazu sollte entweder eine vollständige Läsion oder eine Probebiopsie, die den anulären Rand und das Zentrum enthält, untersucht werden.

\section{Therapie}

Die Behandlung ist schwierig und häufig unbefriedigend $[43,44]$. Mit wechselndem Erfolg wurden topische und intraläsionale Glukokortikoide, eine Fototherapie mit PUVA und UVB $311 \mathrm{~nm}$ sowie systemische Behandlungen mit Chloroquin, Dapson, Clofazimin und Ciclosporin eingesetzt. 


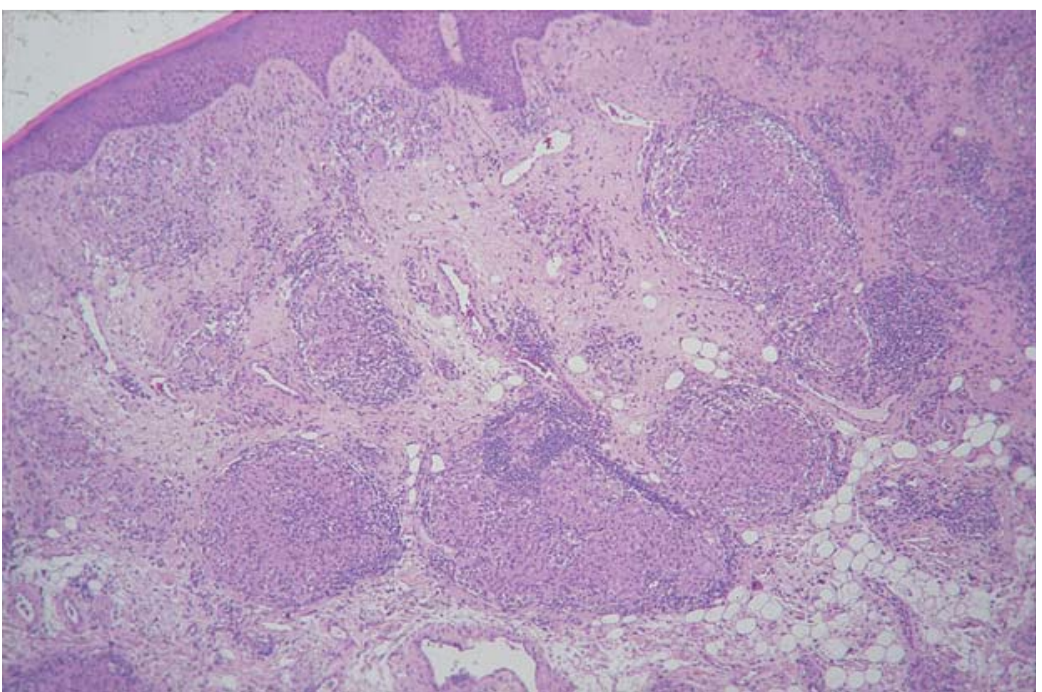

Abb.12 Histologie des kutanen Morbus Crohn mit entzündlichen umschriebenen Granulomen in der Dermis (HE-Färbung, Originalvergrößerung 100×).
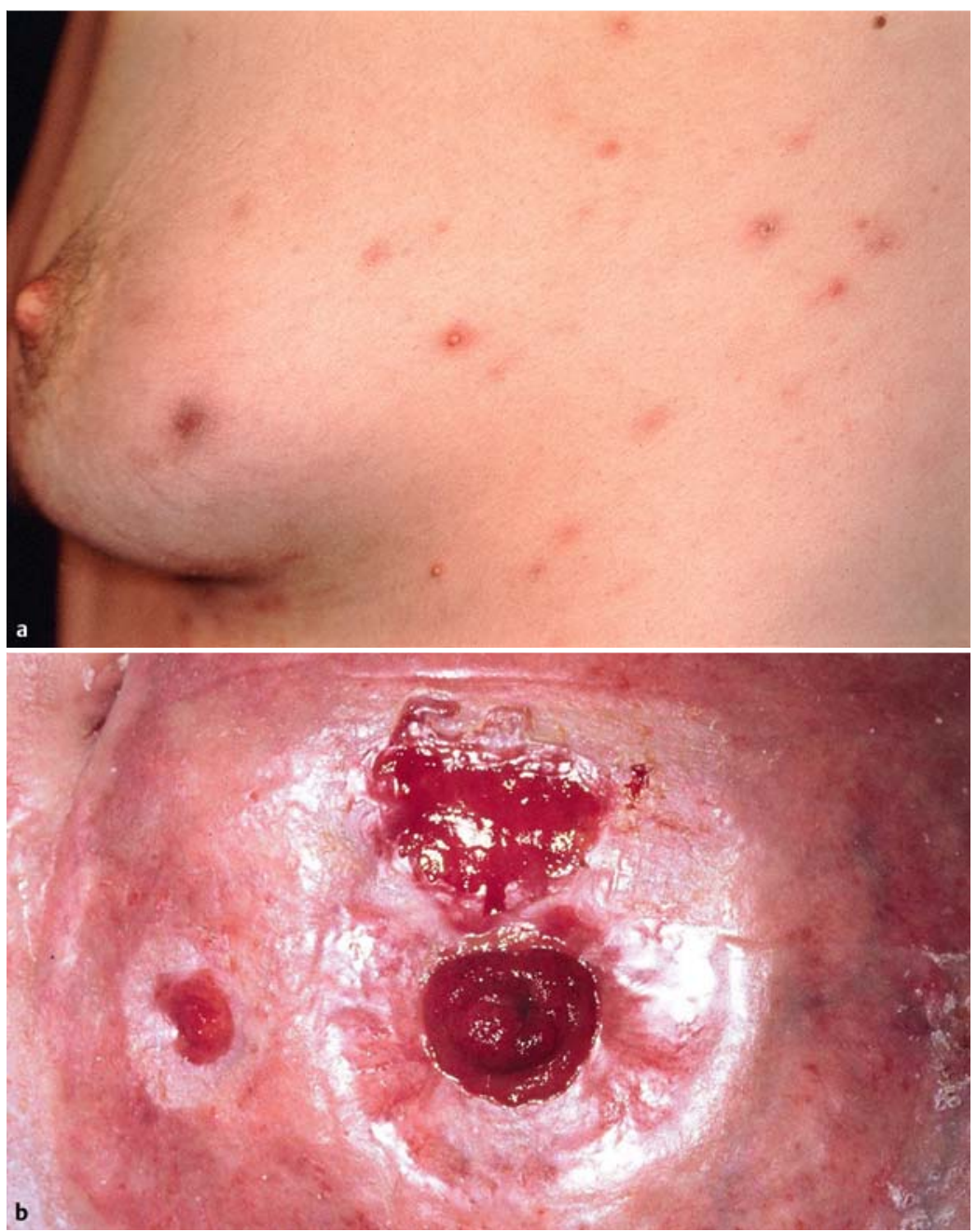

Abb.13 Metastatischer Morbus Crohn. a Pustulöse und ulzerierte Papeln am seitlichen Thorax. b Großer ulzerierter Knoten am Stamm [55].
Bei einzelnen Patienten wurde eine spontane Rückbildung mit fleckförmigen Pigmentverschiebungen beobachtet.

\section{Kutaner Morbus Crohn}

Etwa 10-20\% der Patienten mit Morbus Crohn weisen Veränderungen an der Haut und Schleimhaut auf [49]. Unterschieden werden:

- spezifische granulomatöse Infiltrate an der Haut und Schleimhaut

- nicht spezifische reaktive Entzündungen wie Erythema nodosum und Pyoderma gangraenosum

- durch Malabsorption bedingte Dermatosen wie ein erworbenes Zinkmangelsyndrom Die granulomatösen Infiltrate finden sich häufig im Perianalbereich sowie an der oralen und genitalen Schleimhaut. Der metastatische M. Crohn der übrigen Haut ist mit aktuell weniger als 100 beschriebenen Fällen selten, jedoch wichtig, da die Hautläsionen in 20\% der Fälle der Diagnose einer intestinalen Erkrankung vorausgingen [50].

\section{Ätiopathogenese}

Beim intestinalen M. Crohn handelt es sich um eine genetisch bedingte T-Zell-vermittelte granulomatöse Entzündung vom Th1-Typ auf kommensale Enterobakterien [51]. Es wird vermutet, dass sich diese abnorme Immunreaktion auch an der Haut nach Eindringen der Keime abspielt.

\section{Histopathologie}

In der Dermis und im subkutanen Fettgewebe imponieren umschriebene und solide Granulome aus Histiozyten und wenigen mehrkernigen Riesenzellen ( $\bullet$ Abb. 12) [52]. Diese Granulome sind von Lymphozyten, Plasmazellen und auch eosinophilen Granulozyten ummantelt und häufig in der Umgebung der Blutgefäße lokalisiert. Bei ulzerierten Läsionen finden sich zudem vaskulitische Veränderungen mit nekrobiotischen Granulomen [52].

\section{Klinik}

Das klinische Bild ist außerordentlich variabel und daher selten diagnostisch $[49,50,53,54]$. Es reicht von erythematösen Schwellungen im Oralund Genitalbereich über schnell ulzerierende und vegetierende Plaques im Perianalbereich und in der Umgebung von operativen abdominellen Eingriffen bis zu rötlichen Knötchen, Knoten und Plaques beim metastatischen M. Crohn $(\bullet$ Abb.13a). Diese Infiltrate können im Verlauf ebenfalls ulzerieren und sich dann als Ulzera mit unterminierten Rändern darstellen ( $\bullet$ Abb.13b). Bevorzugte Lokalisationen des metastatischen M. Crohn sind die Extremitäten und Intertrigines [49]. Bei wenigen Patienten traten disseminierte Läsionen am gesamten Integument auf. 


\section{Diagnose}

Aufgrund des variablen klinischen Bildes ist eine klinische Diagnose kaum möglich. Entscheidend ist vielmehr, an einen kutanen M. Crohn als primäre oder sekundäre Manifestation zu denken und gezielt nach Darmbeschwerden zu fragen. Die eindeutige Diagnose kann nur histologisch an einer möglichst nicht ulzerierten Hautläsion gestellt werden.

\section{Therapie}

Der kutane M. Crohn wird wie die Grundkrankheit mit systemischen Glukokortikoiden, Sulfasalazin, Azathioprin, Methotrexat und TNF- $\alpha$-Antagonisten behandelt. Die Therapie sollte in enger Kooperation mit einem Gastroenterologen durchgeführt werden.

Bei unklaren entzündlichen Schwellungen im Mundund Genitalbereich und bei schnell ulzerierenden Hautinfiltraten sollte ein kutaner Morbus Crohn in Erwägung gezogen werden.

\section{Fremdkörpergranulome}

$\nabla$

Fremdkörpergranulome sind die häufigsten nichtinfektiösen granulomatösen Erkrankungen der Haut. Sie werden durch

- körpereigene Materialien wie frei in der Dermis liegende Haare und Nägel sowie durch Hornmaterial aus rupturierten Zysten und

- körperfremde Materialien wie chirurgisches Nahtmaterial, Material für plastisch-chirurgisch-ästhetische Behandlungen (Silikon, Kollagen, andere Füllmaterialien), organische Tier- und Pflanzenstacheln, Holz, Tätowierungsfarbstoffe und metallische Zusatzstoffe von intra- und subkutanen Medikamenten hervorgerufen.

latrogen verursachte Fremdkörpergranulome durch plastisch-chirurgisch-ästhetische Behandlungen haben in den letzten Jahren deutlich zugenommen [56].

\section{Ätiopathogenese}

Nach einer initialen granulozytären Entzündung entstehen nicht-allergische oder allergisch bedingte Granulome $[57,58]$. Die deutlich häufigeren nicht-allergischen Granulome sind Folge der unspezifisch entzündlichen Eigenschaften der Fremdkörper. Bei den allergischen Granulomen wirken die Fremdkörper als Antigen und lösen eine T-Zell-vermittelte Immunreaktion vom Th1Typ aus. Allergische Granulome entstehen vor allem durch Tätowierungsfarbstoffe und Aluminium in Impfstoffen und Immuntherapeutika.

\section{Histopathologie}

In der Initialphase finden sich in der Umgebung des Fremdkörpers ausgeprägte und abszessartige Infiltrate aus neutrophilen Granulozyten [57].
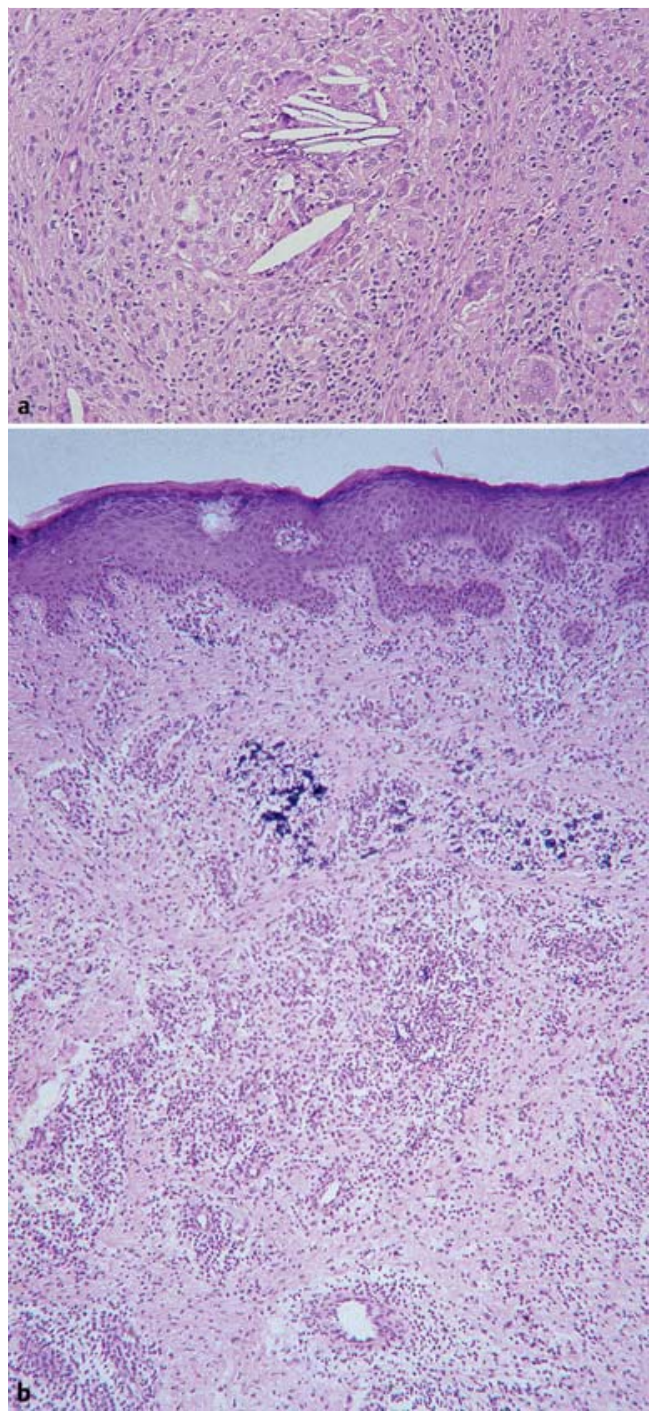

Nicht-allergische Granulome sind durch zahlreiche mehrkernige Riesenzellen, denen zumeist Neutrophile beigemengt sind, gekennzeichnet ( $\bullet$ Abb. 14a) [57]. Die T-Zell-vermittelten allergischen Reaktionen imponieren als interstitielle granulomatöse Entzündung ( $\boldsymbol{A} \mathbf{A b b} . \mathbf{1 4 b}$ ) oder als umschriebene sarkoidale und tuberkuloide Granulome [57]. Die Fremdkörper können häufig bereits in histologischen Routinepräparaten erkannt und identifiziert werden. Wenn dies nicht der Fall ist, wird unter polarisiertem Licht nach doppelbrechendem Fremdmaterial gesucht oder das Material wird durch histochemische Färbungen dargestellt.

\section{Klinik}

Die klinischen Erscheinungen sind vielfältig [5860].Zu Beginn zeigen sich am Ort der Implantation rote bis hochrote, zumeist deutlich schmerzhafte Erytheme, Knoten und Abszesse. Später imponieren rote bis braunrote, weniger schmerzhafte Knoten und Plaques ( $\bullet$ Abb.15a). Diese können sekundär ulzerieren. Bei chirurgischem Nahtmaterial und Haareinsprengungen werden auch fistelnde chronische Wunden und Granuloma pyogenicum-
Abb. 14 Histologie von Fremdkörpergranulomen. a Nicht-allergische Reaktion auf Holzsplitter mit zahlreichen mehrkernigen Riesenzellen an der Peripherie (HE-Färbung, Originalvergrößerung 200×). b Allergische Reaktion auf blauschwarze Tätowierungsfarbe mit diffuser granulomatöser Entzündung in der Dermis (HE-Färbung, Originalvergrößerung 100×).

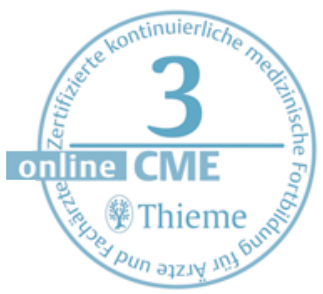


Abb. 15 Fremdkörpergranulome. a Knotiges Granulom durch Holzsplitter. b Subkutanes Granulom durch Implantation von Silikon.
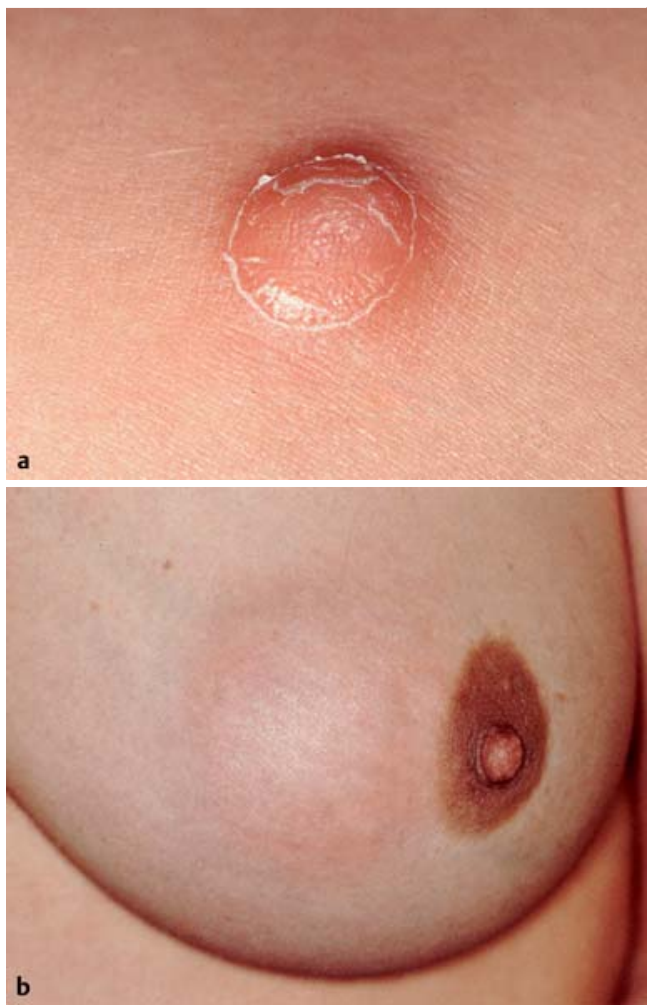

ähnliche exophytische Tumoren beobachtet [61, 62]. Persistierende subkutane Knoten finden sich nach Impfungen mit aluminiumhaltiger Vakzine und nach Injektion von synthetischen Füllmaterialien ( $\bullet$ Abb.15b). Bei Tätowierungsfarbstoffen wurden zudem sogar lichenoide allergische und fotoallergische Kontaktekzeme beschrieben [63].

\section{Diagnose}

Eine ausschließlich klinische Diagnose ist nur bei eindeutiger Anamnese zulässig. Wichtig ist, bei lokalisierten entzündlichen Knoten und Plaques und bei unklaren chronischen Wunden an ein Fremdkörpergranulom zu denken und eine histologische Untersuchung zu veranlassen. In vielen Fällen kann durch die Histologie auch die Art des Fremdkörpers identifiziert werden. Zur eindeutigen Identifikation stehen im Bedarfsfall verschiedene aufwendige physikochemische Untersuchungsverfahren (Infrarotspektroskopie, energiedispersive Röntgenspektroskopie, Elektronenenergieverlustspektroskopie) zur Verfügung [58]. Bildgebende Verfahren wie Ultraschall, Computertomografie und Magnetresonanztomografie sind nur selten diagnostisch, da die zumeist kleinen Fremdkörper nicht erfasst werden.

\section{Therapie}

Behandlung der Wahl ist die vollständige chirurgische Entfernung des Fremdkörpers. Granulomatöse Reaktionen auf metallische Zusatzstoffe von Impfstoffen und Medikamenten und nach injizierten Füllmaterialien können mit intraläsionalen Glukokortikoiden behandelt werden $[64,65]$.
Fremdkörpergranulome sind die häufigsten granulomatösen Dermatosen und zeigen vielfältige Hauterscheinungen.

\section{Interessenkonflikt}

Der Autor gibt an, dass kein Interessenkonflikt besteht.

\section{Kernaussagen}

Granulomatöse Dermatosen sind nicht-infektiöse, chronisch-entzündliche Hautkrankheiten mit manchmal typischem, häufig jedoch nicht diagnostischem klinischen Erscheinungsbild. Entscheidend ist, bei allen unklaren rötlichen bis braunroten, rundovalen bis ringförmig angeordneten, soliden und ulzerierten Knötchen, Knoten und Plaques an eine granulomatöse Dermatose zu denken und eine histologische Untersuchung zur Sicherung bzw. zum Ausschluss der Diagnose zu veranlassen. Andere Laborverfahren und bildgebende Untersuchungen haben keine diagnostische Bedeutung. Die Behandlung basiert bei allen granulomatösen Dermatosen ausschließlich auf empirischen Daten und umfasst topische, physikalische und systemische Maßnahmen mit breiter anti-inflammatorischer Wirkung. Gezielte und damit effektivere Therapieansätze sind erst dann zu erwarten, wenn genau geklärt ist, wodurch die jeweilige granulomatöse Entzündung ausgelöst und unterhalten wird.

\section{Literatur}

1 Izikson L, English JC. Noninfectious granulomatous diseases: an update. Adv Dermatol 2006; 22: 31-35

2 Weedon $D$. The granulomatous reaction pattern. In: Weedon D, Hrsg. Weedon's Skin Pathology. London: Churchill Livingstone; 2010: 170

3 Adams DO. The granulomatous inflammatory response. A review. Am J Pathol 1976; 84: 164-192

4 lannuzzi MC, Rybicki BA, Teirstein AS. Sarcoidosis. N Engl J Med 2007; 357: 2153-2165

5 Bordignon M, Rottoli P, Agostini C et al. Adaptive immune responses in primary cutaneous sarcoidosis. Clin Dev Immunol 2011; DOI: 10.1155/2011/235142

6 Saidha S, Sotirchos ES, Eckstein C. Etiology of sarcoidosis: does infection play a role? Yale J Biol Med 2012; 85: $133-141$

7 Weedon D. Sarcoidosis. In: Weedon D, Hrsg. Weedon's Skin Pathology. London: Churchill Livingstone; 2010: $171-173$

8 Calonje E. Sarcoidosis. In: Calonje E, Brenn T, Lazar A et al., Hrsg. McKee's Pathology of the Skin. Philadelphia: Elsevier Saunders; 2012: 281-288

9 Haimovic A, Sanchez M, Judson MA et al. Sarcoidosis: a comprehensive review and update for the dermatologist: part I. Cutaneous disease. J Am Acad Dermatol 2012; 66: 699.e1-699.e18

10 Gawkrodger DJ. Sarcoidosis. In: Burns T, Breathnach S, Cox $\mathrm{N}$ et al., Hrsg. Rook's Textbook of Dermatology. Hoboken: Wiley-Blackwell; 2010: 61.1-61.23 
11 Mempel M. Sarkoidose. In: Plewig G, Landthaler M, Burgdorf WHC et al., Hrsg. Braun-Falco's Dermatologie, Venerologie und Allergologie. Berlin, Heidelberg: Springer; 2012: $671-678$

12 Reisenauer A, White KP, Korcheva Vet al. Sarcoidosis. In: Bolognia JL, Jorizzo JL, Schaffer JV, Hrsg. Dermatology. Amsterdam: Elsevier; 2012: 1557-1563

13 Röcken M, Schaller M, Burgdorf W. Taschenatlas Dermatologie. Stuttgart: Thieme; 2010

14 Buechner SA, Winkelmann RK, Banks PM. Identification of T-cell subpopulations in granuloma annulare. Arch Dermatol 1983; 119: 125 - 128

15 Fayyazi A, Schweyer S, Eichmeyer B et al. Expression of IFN-gamma, coexpression of TNF-alpha and matrix metalloproteinases and apoptosis of T lymphocytes and macrophages in granuloma annulare. Arch Dermatol Res 2000; 292: $384-390$

16 Weedon D. Granuloma annulare. In: Weedon D, Hrsg. Weedon's Skin Pathology. London: Churchill Livingstone; 2010: 177-181

17 Calonje E. Granuloma annulare. In: Calonje E, Brenn T, Lazar A, et al. Hrsg. McKee's Pathology of the Skin. Philadelphia: Elsevier Saunders; 2012: $288-295$

18 Prendiville JS. Granuloma annulare. In: Wolff K, Goldsmith LA, Katz SI et al., Hrsg. Fitzpatrick's Dermatology in General Medicine. New York: McGrawHill; 2008: 369 -373

19 Burns DA. Granuloma annulare. In: Burns T, Breathnach S, Cox N et al., Hrsg. Rook's Textbook of Dermatology. Hoboken: Wiley-Blackwell; 2010: 60.1 60.12

20 Mempel M. Granuloma anulare. In: Plewig G, Landthaler M, Burgdorf WHC et al., Hrsg. Braun-Falco's Dermatologie, Venerologie und Allergologie. Berlin, Heidelberg: Springer; 2012: 678-680

21 Reisenauer A, White KP, Korcheva V et al. Granuloma annulare. In: Bolognia JL, Jorizzo JL, Schaffer JV et al., Hrsg. Dermatology. Amsterdam: Elsevier; 2012: 1563 - 1566

22 Thornsberry LA, English JC 3rd. Etiology, diagnosis, and therapeutic management of granuloma annulare: an update. Am J Clin Dermatol 2013; 14: $279-290$

23 Hawryluk EB, Izikson L, English JC 3rd. Non-infectious granulomatous diseases of the skin and their associated systemic diseases: an evidence-based update to important clinical questions. Am J Clin Dermatol 2010; 11: 171 - 181

24 Calzavara-Pinton PG, Rossi MT, Aronson E et al. Italian Group For Photodynamic Therapy. A retrospective analysis of real-life practice of off-label photodynamic therapy using methyl aminolevulinate (MAL-PDT) in 20 Italian dermatology departments. Part 1: inflammatory and aesthetic indications. Photochem Photobiol Sci 2013; 12: 148-157

25 Weisenseel P, Kuznetsov AV, Molin Setal. Photodynamic therapy for granuloma annulare: more than a shot in the dark. Dermatology 2008; 217: 329-332

26 Reid SD, Ladizinski B, Lee K et al. Update on necrobiosis lipoidica: a review of etiology, diagnosis, and treatment options. J Am Acad Dermatol 2013; 69: $783-791$

27 Ngo B, Wigington $G$, Hayes $K$ et al. Skin blood flow in necrobiosis lipoidica diabeticorum. Int J Dermatol 2008; 47: 354-358

28 Boateng B, Hiller D, Albrecht HP et al. Cutaneous microcirculation in pretibial necrobiosis lipoidica. Comparative laser Doppler flowmetry and oxygen partial pressure determinations in patients and healthy controls. Hautarzt 1993; 44: 581 - 586

29 Weedon D. Necrobiosis lipoidica. In: Weedon D, Hrsg. Weedon's Skin Pathology. London: Churchill Livingstone; 2010: 181-183

30 Calonje E. Necrobiosis lipoidica. In: Calonje E, Brenn T, Lazar A et al., Hrsg. McKee's Pathology of the Skin. Philadelphia: Elsevier Saunders; 2012: 295-299

31 Burns DA. Necrobiosis lipoidica. In: Burns T, Breathnach S, Cox N et al., Hrsg. Rook's Textbook of Dermatology. Hoboken: Wiley-Blackwell; 2010: 60.1260.17

32 Mempel M. Necrobiosis lipoidica. In: Plewig G, Landthaler M, Burgdorf WHC et al., Hrsg. Braun-Falco's Dermatologie, Venerologie und Allergologie. Berlin, Heidelberg: Springer; 2012: 681-682

33 Reisenauer A, White KP, Korcheva $V$ et al. Necrobiosis lipoidica. In: Bolognia JL, Jorizzo JL, Schaffer JV, Hrsg. Dermatology. Amsterdam: Elsevier; 2012: $1566-1568$

34 Morgan AJ, Schwartz RA. Diabetic dermopathy: A subtle sign with grave implications. J Am Acad Dermatol 2008; 58: 447-451

35 Miteva M, Romanelli P, Kirsner RS. Lipodermatosclerosis. Dermatol Ther 2010; 23: $375-388$

36 O'Brien JP. Actinic granuloma: an annular connective tissue disorder affecting sun- and heat-damaged (elastotic) skin. Arch Dermatol 1975; 111: $460-466$

37 Hanke CW, Bailin PL, Roenigk HM. Annular elastolytic giant cell granuloma. J Am Acad Dermatol 1979; 1: 413-421
38 O'Brien JP, Regan W. Actinically degenerate elastic tissue is the likely antigenic basis of actinic granuloma of the skin and of temporal arteritis. J Am Acad Dermatol 1999; 40: 214-222

39 Meissner $M$, Pinter $A$, Wolter $M$ et al. Multiple orale Papeln und Plaques be einem Patienten mit Morbus Crohn. Akt Dermatol 2012; 38: 33 - 36

40 Weedon D. Elastolytic granulomas. In: Weedon D, Hrsg. Weedon's Skin Pathology. London: Churchill Livingstone; 2010: 188-190

41 Calonje E. Annular elastolytic granuloma. In: Calonje E, Brenn T, Lazar A et al., Hrsg. McKee's Pathology of the Skin. Philadelphia: Elsevier Saunders; 2012: 302

42 Mempel M. Anuläres elastolytisches Riesenzellgranulom. In: Plewig G, Landthaler M, Burgdorf WHC et al., Hrsg. Braun-Falco's Dermatologie, Venerologie und Allergologie. Berlin, Heidelberg: Springer; 2012: 680-681

43 Reisenauer A, White KP, Korcheva V et al. Annular elastolytic giant cell granuloma. In: Bolognia JL, Jorizzo JL, Schaffer JV, Hrsg. Dermatology. Amsterdam: Elsevier; 2012: 1568 - 1570

44 Kowalzick L, Wickenhauser C, Hammerschmidt D et al. Generalisiertes anuläres elastolytisches Riesenzellgaranulom bei hochmalignem B-Zell-Lymphom. Akt Dermatol 2012; 38: 173 - 176

45 Marmon S, O'Reilly KE, Fischer $M$ et al. Papular variant of annular elastolytic giant-cell granuloma. Dermatol Online J 2012; 18: 23

46 Aso Y, Izaki S, Teraki Y. Annular elastolytic giant cell granuloma associated with diabetes mellitus: a case report and review of the Japanese literature. Clin Exp Dermatol 2011; 36: 917 - 919

47 Garg A, Kundu R, Plotkin O et al. Annular elastolytic giant cell granuloma heralding onset and recurrence of acute myelogenous leukemia. Arch Dermatol 2006; 142: 532 - 533

48 Boussault P, Tucker ML, Weschler J et al. Primary cutaneous CD4+ small/medium-sized pleomorphic T-cell lymphoma associated with an annular elastolytic giant cell granuloma. Br J Dermatol 2009; 160: 1126-1128

49 Thrash B, Patel M, Shah KR et al. Cutaneous manifestations of gastrointestinal disease: part II. J Am Acad Dermatol 2013; 68: 211-243

50 Reisenauer A, White KP, Korcheva V et al. Cutaneous Crohn's disease. In: Bolognia JL, Jorizzo JL, Schaffer JV, Hrsg. Dermatology. Amsterdam: Elsevier; 2012: $1570-1571$

51 Sartor RB. Mechanisms of disease: pathogenesis of Crohn's disease and ulcerative colitis. Nat Clin Pract Gastroenterol Hepatol 2006; 3: 390 - 407

52 CalonjeE. Metastatic Crohn's disease. In: CalonjeE, BrennT, Lazar Aetal., Hrsg. McKee's Pathology of the Skin. Philadelphia: Elsevier Saunders; 2012: 309

$53 \mathrm{Cox} \mathrm{NH}$, Coulson IH. Crohn's disease (regional ileitis). In: Burns T, Breathnach S, Cox N, et al. Hrsg. Rook's Textbook of Dermatology. Hoboken: WileyBlackwell; 2010: 62.48-62.50

54 Mempel M. Morbus Crohn der Haut. In: Plewig G, Landthaler M, Burgdorf WHC, et al. Hrsg. Braun-Falco's Dermatologie, Venerologie und Allergologie. Berlin, Heidelberg: Springer; 2012: 683

55 Waltermann K, Marsch WC, Fischer M. Peristomale Dermatitiden. Akt Dermatol 2012; 38: 493-498

56 Requena $L$, Requena $C$, Christensen $L$ et al. Adverse reactions to injectable soft tissue fillers. J Am Acad Dermatol 2011; 64: 1 - 34

57 Glusac EJ, Shapiro PE. Foreign-body reactions. In: Elder DE, Elenitsas R, Johnson BL, et al., Hrsg. Lever's Histopathology of the Skin. Philadelphia: Lippincott Williams and Wilkins; 2005: $384-391$

58 Abdallah MA, Abdallah MMA, Abdallah MAR. Foreign body reactions. In: Bolognia JL, Jorizzo JL, Schaffer JV, Hrsg. Dermatology. Amsterdam: Elsevier; 2012: $1573-1583$

59 Kennedy CTC, Burd DAR, Creamer D. Foreign bodies. In: Burns T, Breathnach S, Cox N, et al., Hrsg. Rook's Textbook of Dermatology. Hoboken: WileyBlackwell; 2010: 28.39-28.51

60 Mempel M. Fremdkörpergranulome. In: Plewig G, Landthaler M, Burgdorf WHC, et al., Hrsg. Braun-Falco's Dermatologie, Venerologie und Allergologie. Berlin, Heidelberg: Springer; 2012: 683-685

61 Halder RM. Pseudofolliculitis barbae and related disorders. Dermatol Clin 1988; 6: $407-412$

62 McCallum DI, Hall GF. Umbilical granulomata - with particular reference to talc granuloma. Br J Dermatol 1970; 83: 151 - 156

63 Kaur RR, Kirby W, Maibach H. Cutaneous allergic reactions to tattoo ink. J Cosmet Dermatol 2009; 8: 295-300

64 García-Patos V, Pujol RM, Alomar A et al. Persistent subcutaneous nodules in patients hyposensitized with aluminum-containing allergen extracts. Arch Dermatol 1995; 131: 1421 - 1424

65 Lemperle G, Gauthier-Hazan N. Foreign body granulomas after all injectable dermal fillers: part 2. Treatment options. Plast Reconstr Surg 2009; 123 $1864-1873$ 


\section{CME-Fragen Granulomatöse Dermatosen}

1 Dermatosen sind gekennzeichnet durch dermale Infiltrate von

A neutrophilen und eosinophilen Granulozyten.

B Histiozyten und Granulozyten.

C Lymphozyten und Granulozyten.

D Histiozyten und mehrkernigen Riesenzellen.

E Histiozyten und Lymphozyten.

Die Bestimmung des Blutspiegels des Angiotensin-konvertierenden Enzyms eignet sich zur

A diagnostischen Sicherung einer Sarkoidose.

B Verlaufskontrolle einer Sarkoidose.

C diagnostischen Sicherung eines Morbus Crohn.

D Verlaufskontrolle eines Morbus Crohn.

E Verlaufskontrolle einer Necrobiosis lipoidica.

Die fotodynamische Therapie ist ein viel versprechendes neues Behandlungsverfahren bei

A kutanem Morbus Crohn.

B anulär elastolytischem Riesenzellgranulom.

C Necrobiosis lipoidica.

D Granuloma anulare.

E kutaner Sarkoidose.

4 Das Löfgren-Syndrom bei der Sarkoidose ist die Kombination von

A Erythema nodosum, hilärer Lymphadenopathie und Arthritis.

B Narbensarkoidose, hilärer Lymphadenopathie und Arthritis.

C Lupus pernio, hilärer Lymphadenopathie und Arthritis.

D subkutaner Hautsarkoidose, hilärer Lymphadenopathie und Arthritis.

E kleinknotiger Hautsarkoidose, hilärer Lymphadenopathie und Arthritis.

Palisadengranulome sind ein typischer histologischer Befund bei

A Fremdkörpergranulomen.

B Sarkoidose.

C Morbus Crohn.

D anulär elastolytischem Riesenzellgranulom.

E Necrobiosis lipoidica.
6 Unter einem metastatischen Morbus Crohn versteht man Hautveränderungen

A an der Mundschleimhaut.

B im Perianalbereich.

C in der Umgebung von abdominellen Eingriffen.

D an Extremitäten und Stamm.

E im Genitalbereich.

7 Ulzerierte Knoten und Plaques mit unterminierten Rändern sind klinischer Hinweis auf

A eine Sarkoidose.

B eine Necrobiosis lipoidica.

C ein perforierendes Granuloma anulare.

D einen Morbus Crohn.

E Fremdkörpergranulome.

8 TNF- $\alpha$-Antagonisten werden nicht eingesetzt bei der Behandlung

A einer Sarkoidose.

B eines Granuloma anulare.

C einer Necrobiosis lipoidica.

D eines Morbus Crohn.

E von Fremdkörpergranulomen.

9 Schmerzlose und hautfarbene subkutane Knoten finden sich bei

A Erythema nodosum.

B Granuloma anulare.

C Necrobiosis lipoidica.

D anulär elastolytischem Riesenzellgranulom.

E Morbus Crohn.

Bei allen ringförmig konfigurierten Dermatosen sollte die Biopsie zur histologischen Untersuchung entnommen werden.

A aus dem Zentrum der Läsion

B aus Zentrum und Rand der Läsion

C aus dem Rand der Läsion

D aus dem Rand der Läsion und der benachbarten Normalhaut

E aus Zentrum und Rand der Läsion und benachbarter Normalhaut 